\title{
Analysis of Solar and Windmill Using Real Time Simulation Tool
}

\author{
M.Pushpavalli ${ }^{*}$,P.Abirami ${ }^{2}$, P.Sivagami ${ }^{3}$, Sundarsingh JebaseelanS D ${ }^{4}$, Sayan Ghosh ${ }^{5}$,Oruganti V V \\ L N Karthik ${ }^{6}$ \\ (pushpavalli.eee@sathyabama.ac.in ${ }^{1}$,abiramiramkumar80@gmail.com², ${ }^{2}$ ivagamitec@gmail.com ${ }^{3}$, sun \\ darsingh.eee@sathyabama.ac.in ${ }^{4}$, rkartik67@gmail.com ${ }^{5}$,akshayguptha1437@gmail.com6 ${ }^{6}$ )
}

Assistant Professor/EEE Sathyabama Institute of Science \& Technology ${ }^{1,2,3}$, Associate Professor/EEE Sathyabama Institute of Science \& Technology ${ }^{4}$,UG Scholar/EEE Sathyabama Institute of Science \& Technology 5,6

\begin{abstract}
This work is concerned with modelling and modification of a wind power production method into a solar-wind composite mode along with analysis and simulation of the proposed method. The suggested Wind turbine is modelled, and parameters such as rotor diameter, wind speed, pitch angle, etc are taken into count. The PV module is then modeled based on general parameters such as solar irradiation and temperature, etc. A PVsyst simulation is performed for the solar PV grid and stand alone system. Further homer grid software is used to perform simulation on the hybrid system and the results were observed. The hybrid system has an output $1.5 \mathrm{kw}$ or $1500 \mathrm{w}$ which consists of wind turbines $(500 \mathrm{kw})$ and PV solar system of 6 panels of $165 \mathrm{w}$ each producing the total peak output of $1 \mathrm{kw}$ or $1000 \mathrm{w}$. Autocontollers and converters are used along with a battery of $155 \mathrm{w}$ for storage. Conclusions point that the load absorbs power from both solar and wind schemes. However, there is the fluctuation of power supply in some driving conditions, such as modification of solar radiation and wind velocity
\end{abstract}

Keywords: Wind Energy Generating System, Solar, PV-Wind Hybrid System.

\section{Introduction}

First and foremost, wind is an unlimited, free and both wind and solar energies are utilised to operate the load. Solar energy is eco friendly.It can be installed in areas where Building heights is prohibited. The solar panels harmlessly generate electricity and iincreases the overall efficiency of the system. Solar can be operated in absence of wind. When both wind and solar energies are unavailable then the energy stored in the battery can be utilised to operate the load. The overall power factor of the system is increased and losses are reduced. Proposed This Control Strategy Used In Pumping And Smart House Applications [1]. Transformer. Reduce Total Cost. Investigates the possible synchronous generator based wind power production mode providing a separate load managing recent innovation [2-3]. To Produce A Stable Energy From Solar -wind Hybrid System By Using A Sliding Mode Controller Which Works With Better Efficiency In Rural Areas[4]. Includes some fuzzy logic controller with MPPT algorithm to improve this effective risk following complex and transient conditions [5]. The Types Converters Like DC-DC, PFAC, HFAC \& Hybrid DC-PFAC Which Solves The Typical Issues Of The Hybrid System Management[6].Generation of 
maximum power from less energy using microgrid technology[7].Solar/Wind scheme for Power utilization for Rural regions. Production of Energy Using Both Wind And Solar To Achieve Higher Efficiency With Stable Output[8].An innovative Hybrid Methodology To Optimize the wind turbine installation. Increasing Annual Energy Production(AEP) By Generating Huge Amount Of Energy In Wind Forms[9]. A KY(Buck-boost)Converter To Analysing The Hybrid System Generating Higher Output [10-11].This Paper Presents An Advanced Consolation Of Hybrid System So That Demand For More Power Generation Could Be Fulfilled[12]. To Optimize The Energy utilization According the power availability and load profile For this applications the intelligent Controller Determines the utilization of Multisource Energy System[13]-[15].

\section{Using Homer PRO Application}

HOMER PRO programming is a useful asset for structuring and arranging of HRES so as to decide the ideal size of its segments via doing the techno-monetary examination. HOMER likewise considers Hybrid sunlight based in the network associated and independent modes. The average setup and structure in HOMER have appeared here. Required info information for re-enactment with HOMER and furthermore a complete system to show how ideal sizes of half and half sunlight based gear is controlled by HOMER is depicted in this area.Solar Radiation test has been done by referring to the website "HOMER PRO software" and " PVSYST 6.86 software" by locating our collage. The solar radiation with the input and output has been taken for both one month and each month of a year(I.e from January to December 2020). The below-mentioned simulations show all about the radiation input and output with efficiency and accuracy.

Using HOMER PRO software we have connected all the components directly to the bus and then the output has been converted and directly taken to the consumer side. Initially we have connected the PV to the DC Windmill to the AC bus. Thereafter, we have connected the loads and converter as per the specification with the tariff as power the local electricity cost.

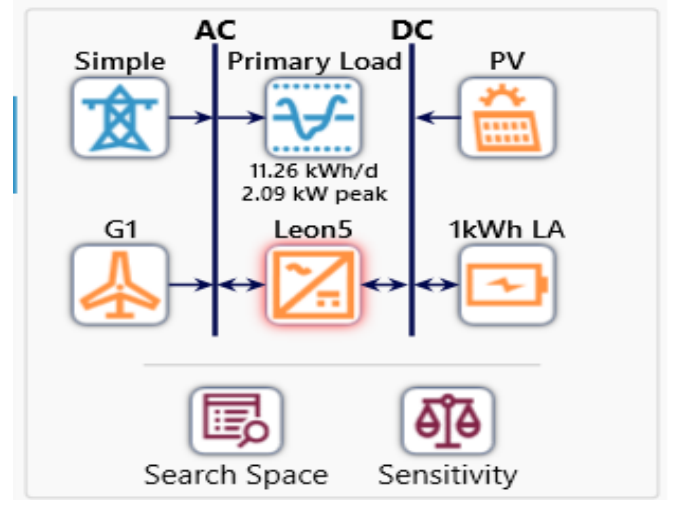

Fig. 1.Block Diagram of Homer Application.

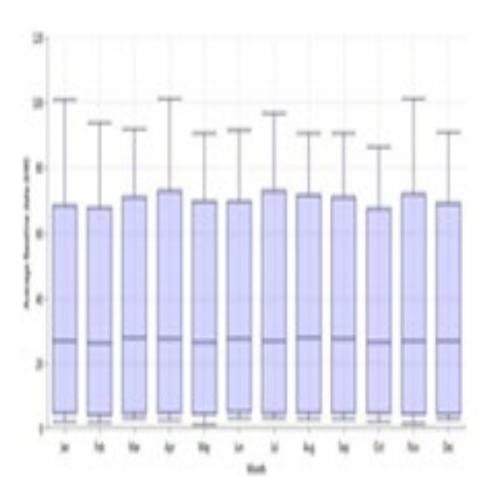

Fig. 2.Load for a complete year

By alluding the heap profile utilizing HOMER programming it has given a tremendous amount of vitality as a normal estimation of the day by day vitality consumption( $\mathrm{kWh} / \mathrm{day})$ 
taken between these seasons. The vitality load request of this region appears here. It is seen that the pinnacle months are April, July, and November and the occurred top burdens have appeared. The enormous interest happens during the peak season that is between July to November.

The heap profile of every district is the most significant factor in reproduction and advancement. A few areas, for example, colleges, Factories, medical clinics, lodgings, and industrial areas have genuine burden utilization information, which are fitting for reproduction. This genuine information is taken care of into HOMER as time arrangement information or as a boundary. In any case, in certain locales particularly remote zones and rustic zones, the genuine burden utilization information is not accessible, the heap profile ought to be determined with a notification to the detail of that district, relies upon which the force will be created. This information is taken care of into HOMER as everyday profile and HOMER uses them in power balance oblige.

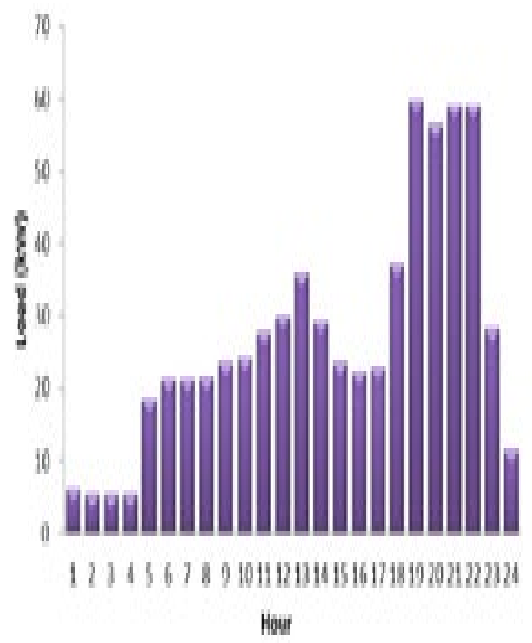

Fig. 3. Load Profile Daily

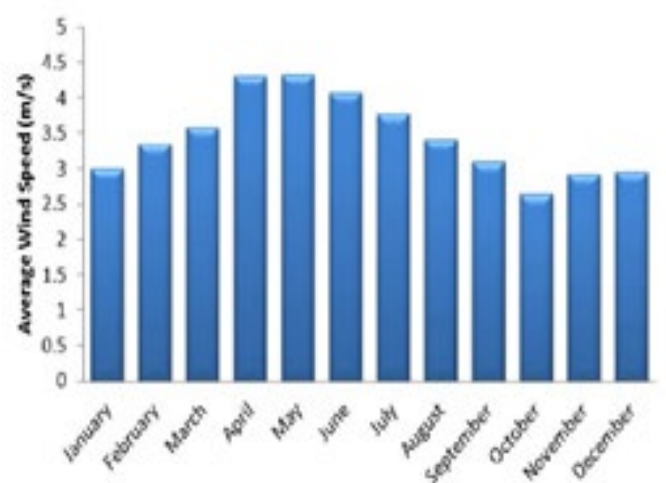

Fig. 4. Wind speed (Monthly)Average

HOMER models a wind turbine as a gadget that changes over the active vitality of the wind into ac or dc power as per a specific force curve.This fig. 4 gives a model force bend. HOMER expect that the force bend applies at a standard air, which compares to standard temperature and weight conditions. Every hour, HOMER computes the force yield of the wind turbine in a four-advance procedure. 


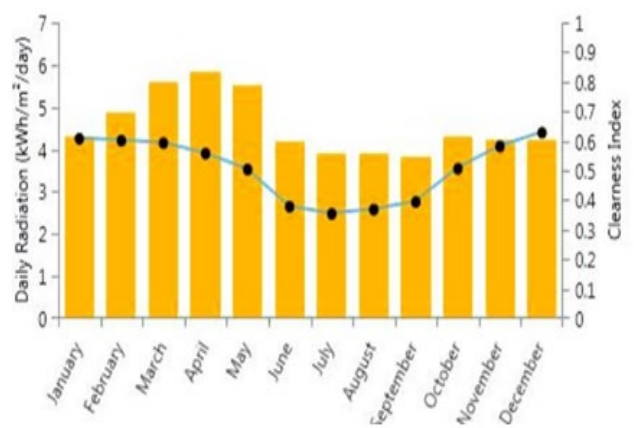

Fig. 5. Solar irradiation and Clearness Index

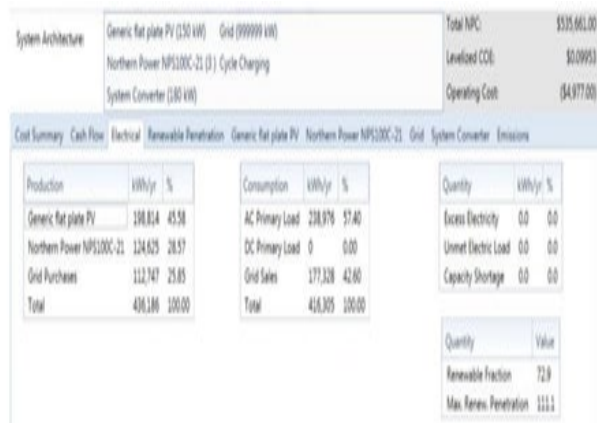

Fig.6.Snapshot of the Production

(Monthly) and Consumption scenario.

HOMER shows the normal yearly wind speed, fuel cost, and sun-powered radiation for the affectability factors that appeared in cost estimation and streamlining table. It is then utilized in the improvement procedure to get the best design of a half and half sustainable power source framework comprising of wind turbines, PV cluster frameworks, battery stockpiling as well as force converter. For this situation study, the framework comprising of a wind turbine, battery stockpiling, and additionally power converter respects the most conservative expense with the base TNPC and a base Cost of Energy (COE). Be that as it may, the TNPC and COE will become costly when the PV cluster framework is remembered for the framework. The vitality got from various parts of a crossover sustainable power source framework is appeared in Fig. The wind turbine delivered a sum that is $60 \%$ of the all-out vitality served. The staying $40 \%$ of all-out vitality is served by utilizing EB stockpiling. This framework delivered $11.3 \%$ of inordinate vitality and $0.1 \%$ of limit lack.

\section{Using PV SYST 6.8.6 Application}

As we couldn't get the official PVsyst 6.8.6 application, we used the trial version of this application where some of the specifications are not available. Initially, after opening the trial version of the application the design type has been chosen. Then the area of connection has been chosen (for this application stand alone). Before that, we have tried for both the stand alone system and the grid system. But, the stand alone system gives better output and its more efficient, so we have simulated and implemented the stand alone system. Thereafter, the database and parameters need to be chosen and then all the system variant has been perfected as per the simulation needed. This particular simulation gives all the information about maximum radiation angle(tilt angle), latitude, longitude, characteristics of the PV array, efficiency of the panel, etc. Moreover, it also shows the battery management system, loss management factors, gives information about the charging and discharging of the controller. Furthermore, the best and most valuable point of this simulation is, it gives exact and accurate information about the input/output at the panels and load usage and tariff. The result has been shown below. 


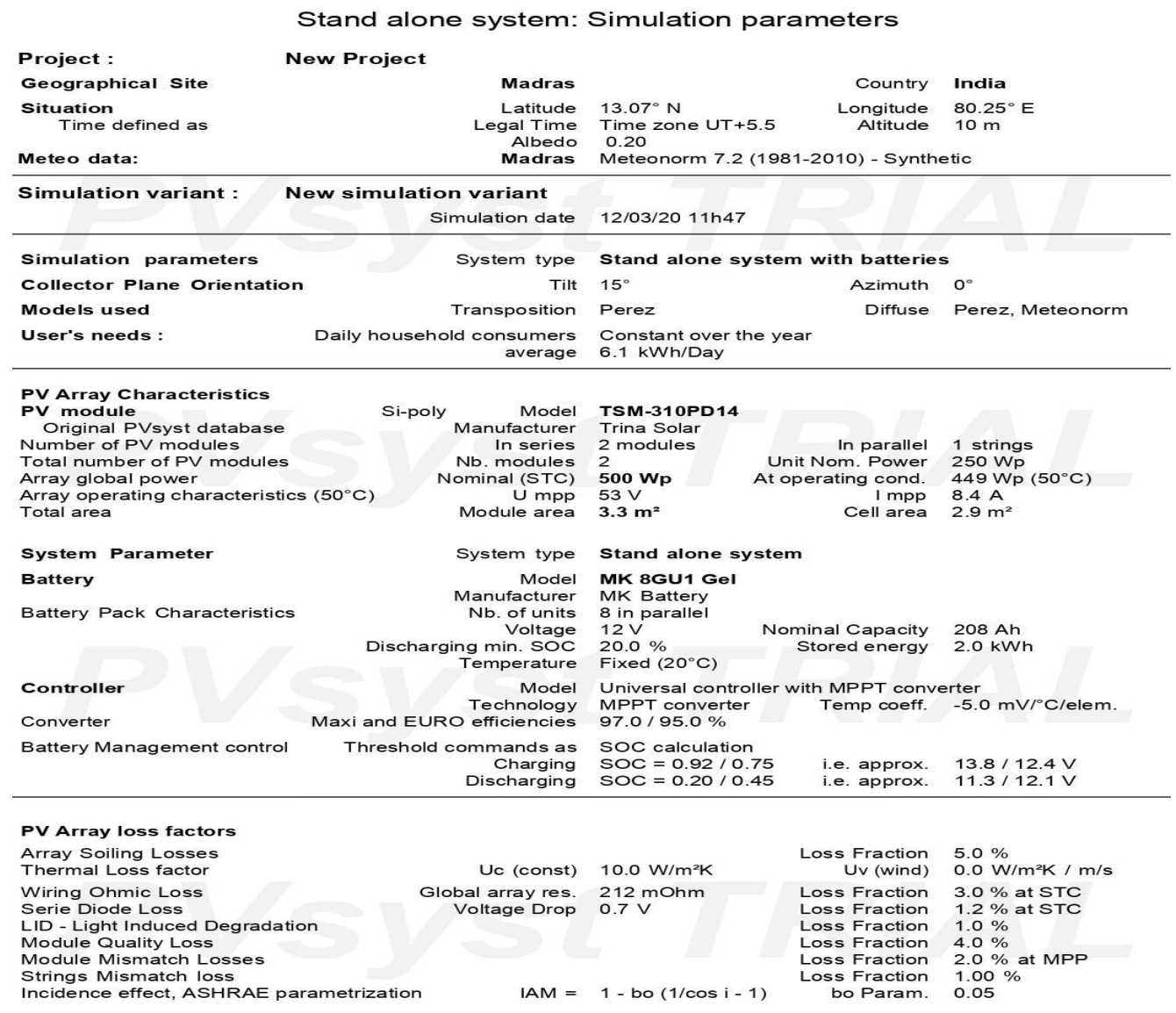

Fig. 8. PV SYST Specifications

If there should be an occurrence of PVsyst, reenacted execution of $1 \mathrm{~kW}$ remain solitary Si-poly photovoltaic framework is done in this investigation utilizing the PVsyst 6.8.6 programming, which gives all the data on

- Annual premise vitality creation that is infused into the boards with explicit items on a yearly premise for each introduced $\mathrm{kW}$.

- Maximum vitality infused into the boards on a month to month premise. for the arranged area.

- From the outcomes, it tends to be reasoned that the arranged PV framework will give the operational advantages to the installer or proprietor.

- Further, the examination can be completed utilizing distinctive PV module advances with fitting establishment strategies for improving the exhibition.

So as to produce what is indicated here the "PVSYST Standard Model" for the module type under test, default esteems endorsed by PVsyst are utilized for the boundaries. As referenced before, in this model the deliberate, or, proportionally here, the nameplate temperature co-proficient of the most extreme force is additionally embedded into 
PVSYST, In request to decidethe incentive for $\mu \gamma$ by setting the force in PVSYST, which thusly decides the temperature reliance of the displayed. The current paper looked into those articles that have utilized HOMER for the ideal arranging of Analysis of Solar and Windmill Using Real-Time Simulation Tool and PVsyst for exact sunlight-based yield.

\section{Stand alone system: Detailed User's needs}

Project :

New Project

Simulation variant: New simulation variant

Maîn system parameters

PV Field Orientation

PV modules

PV Array

Battery

Battery Pack

System type Stand alone system with batteries

tilt 1

tilt $15^{\circ}$ azimuth

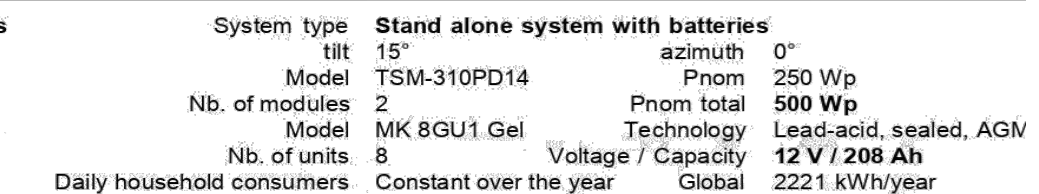

User's needs Daily household consumers Constant over the year

Daily household consumers, Constant over the year, average $=6.1 \mathrm{kWh} / \mathrm{day}$

Annual values

\begin{tabular}{|l|c|c|r|r|}
\hline & Number & Power & Use & \multicolumn{1}{c|}{ Energy } \\
\hline Lamps (LED or fluo) & 10 & $18 \mathrm{~W} / \mathrm{lamp}$ & $12 \mathrm{~h} /$ day & $2160 \mathrm{Wh} /$ day \\
TV / PC / Mobile & 2 & $150 \mathrm{~W} / \mathrm{app}$ & $6 \mathrm{~h} /$ day & $1800 \mathrm{Wh} / \mathrm{day}$ \\
Domestic appliances & 1 & $150 \mathrm{~W} / \mathrm{app}$ & $14 \mathrm{~h} /$ day & $2100 \mathrm{Wh} /$ day \\
\hline Stand-by consumers & & & $24 \mathrm{~h} /$ day & $24 \mathrm{Wh} /$ day \\
\hline
\end{tabular}

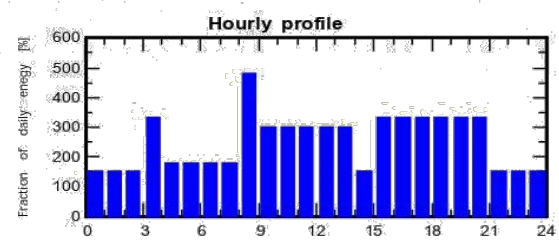

Fig.9. Standalone Parameters

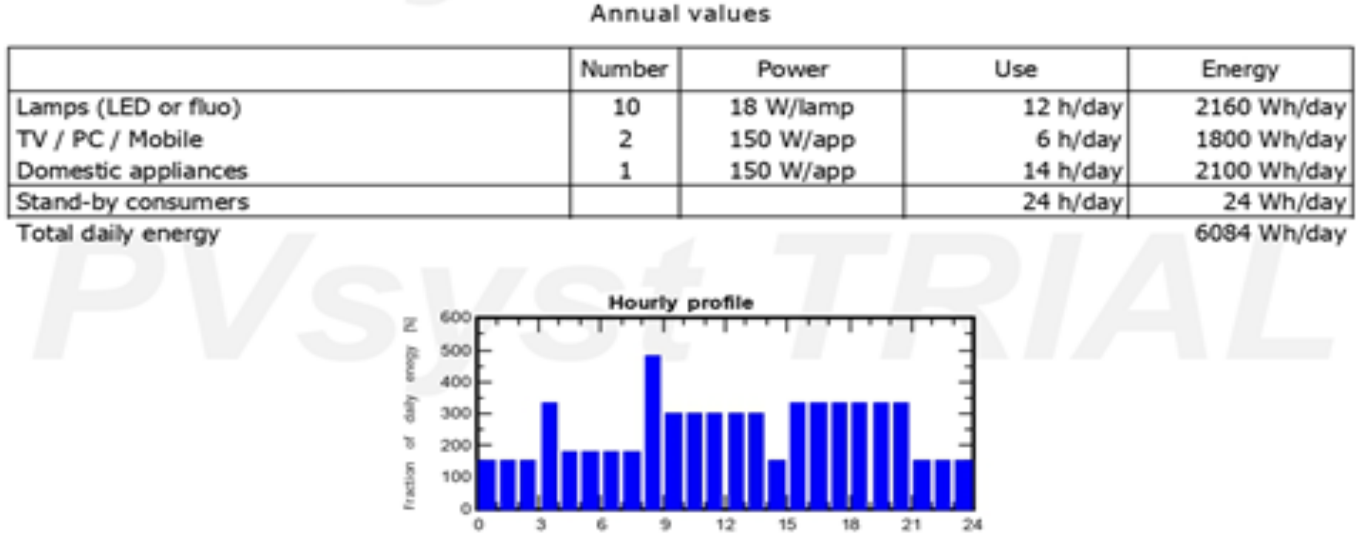

Fig.10. Standalone: Detailed User note 


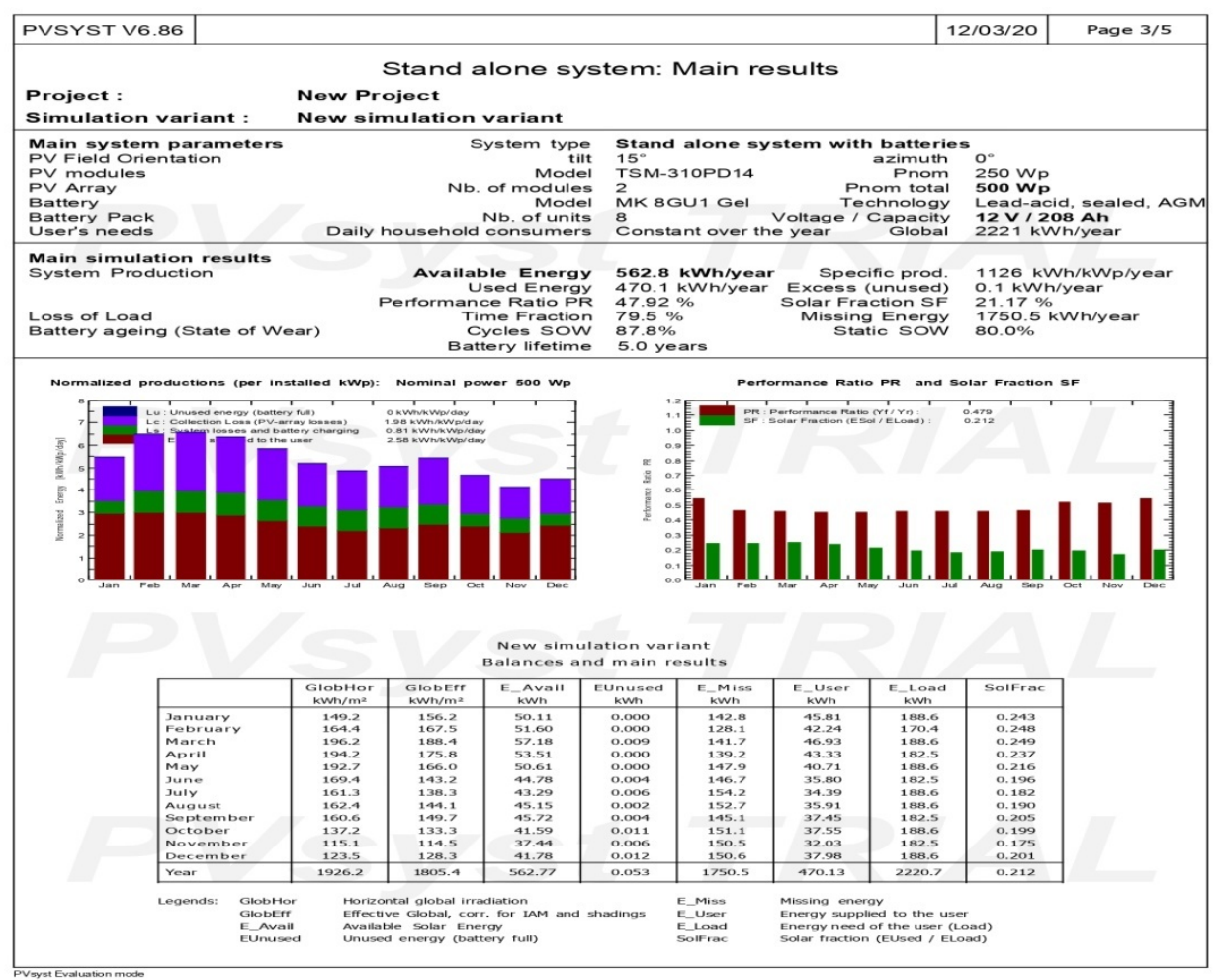

Fig. 11. Stand alone: Main results

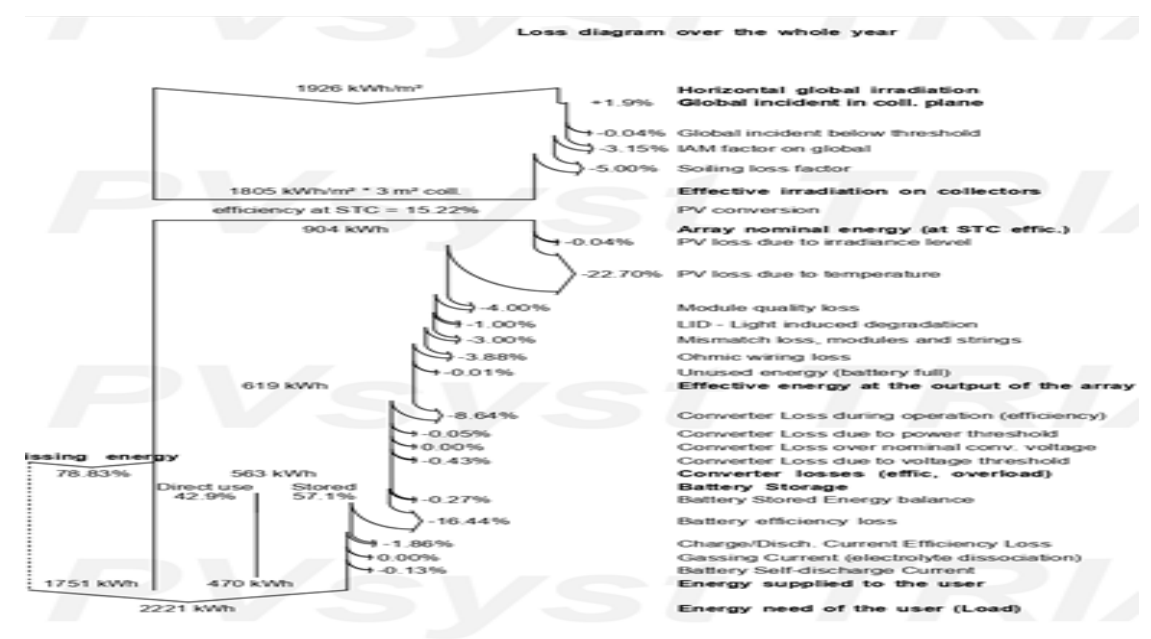

Fig. 12. Standalone: Loss Diagram 


\section{Conclusion}

HOMER PRO Software is a suitable answer for meet the neighborhood loads in rustic, remote, and the urban regions, similar to colleges and medical clinics and enterprises. Deciding the ideal sizes of gear is the significant worry of specialists. HOMER programming is a useful asset utilized by numerous scientists around the globe for ideal arranging of the hybrid framework. As indicated by the capacity and across the board utilization of this product. The product has been utilized in creating nations more than different locales, particularly in remote and provincial zones. The product has been utilized for a wide scope of burden from $0.626 \mathrm{~kW}$ to $2,213,000 \mathrm{~kW}$. PV is a famous asset considered by numerous specialists. The Analysis of PV-Solar And Windmill Using Real-Time Simulation Tool has been demonstrated in an independent mode more than hybrid associated mode. Wind speed, sunlight based radiation, part cost, and essential burden are the most dubious boundaries alluded to in the articles.

\section{References}

[1] A.A.Jadallah D.Y.Mahmood Z.A.Abdulqaedr (2015) - Hybridization Of Solar/Wind Energy System For Power Generation Rural Areas . 2nd International Conference On Computational And Experimental Science And Engineering (Iccesen).

[2] Ali Akbar Ghassami Seyed Mohammad Sadeghzadeh Asma Soleimani (2013) - A High Performance Maximum Power Point Tracker For Pv Systems.Electrical Power and Energy Systems Shahed University,Tehran, Iran.

[3] Asghar Faiz Abdul Rehman (2015) - Hybrid Renewable Energy Systems:Hybridization And Advance Control. 2015 Power Generation System And Renewable Energy Technologies(Pgsret).

[4] B. Wichert et al (2018) - They Have Described About Pv-diesel Hybrid Energy Systems For Remote Area Power Generation - A Review Of Current Practice And Future Developments,"Renew. Sustain. Energy Rev., Vol. 1, No. 3, Pp. 209-228.

[5] C. K. Sao and P. W. Lehn (2018) - They Have Described About A Transformerless Energy Storage System Based On A Cascade Multilevel Pwm Converter With Star Configuration," Ieee Trans. Ind. Appl., Vol. 44, No. 5, Pp. 1621- 1630, "Control And Power Management Of Converter Fed Microgrids," Ieee Trans. Power Systems, Vol. 23, No. 3, Pp. 1088-1098.

[6] Dhanis Woro S.N.G F.Danang Wijaya Sasongko Pramomo Hadi (2014) - Optimal Configuration Of Pv Wind Turbine Grid Battery In Low Potency Energy Resources. 6th International Conference On Ictee,Indonesia.

[7] Bakhsh, F.I. and Khatod, D.K., 2016. A new synchronous generator based wind energy conversion system feeding an isolated load through variable frequency transformer. Renewable Energy, 86, pp.106-116.

[8] J. O. Petinrin Mohamed Shaaban (2013) - A Hybrid Solar Pv -wind Energy System For Voltage Regulation In Micro-grid. 2013 Ieee Student Conference On Research And Development.

[9] K. Agbossou et al (2018) - They Have Suggested Performance Of A Stand-alone Renewable Energy System Based On Energy Storage As Hydrogen," Ieee Transactions On Energy Conversion, Vol. 19, No. 3, Pp. 633 - 640.

[10] M.H. Nehrir C. Wang K. Strunz R.Ramakumar J. Bing Z.Miao Z . Salameh (2011) - A Review Of Hybrid Renewable/Alternative Energy Systems For Electric Special Task Force Of The Ieee Pes Renewable Energy Technologies Subcommittee, Energy Development And Power Generation Committee Ower Generation:Configuration S,Control And Applications.

[11] Pushpavalli.M and N.M Jothi Swaroopan. " KY Converter with Fuzzy Logic Controller For Hybrid Renewable PV/Wind Power System." Transactions on Emerging Telecommunications Technologies (2020): e3989, Volume 31, issue 6.

[12] Zarrad, O., Hajjaji, M.A., Jemaa, A. and Mansouri, M.N., 2019. Sizing Control and Hardware Implementation of a Hybrid Wind-Solar Power System, Based on an ANN Approach, for Pumping Water. International Journal of Photoenergy, 2019. 
[13] Prateek Mittal Kedar Kulkarni Kishalay Mitra (2015) - A Novel Hybrid Optimization Methodology To Optimise The Total Number And Placement Of Wind Turbines. Renewable Energy,Abb Corporate Researchcentre, Mahadevapuram, Bangalore,India.

[14] Neeraj Priyadarshi, Amarjeet Kumar Sharma, Faarooque Azam (2017) - A Hybrid Fireflyasymmetrical Fuzzy Logic Controller Based Mppt For Pv-wind-fuel Grid Integration.International Journals Of Renewable Energy Research.

[15] Illavarason, P. and Sundaram, B.K., 2019, December. A Study of Intrusion Detection System using Machine Learning Classification Algorithm based on different feature selection approach. In 2019 Third International conference on I-SMAC (IoT in Social, Mobile, Analytics and Cloud)(I-SMAC) (pp. 295-299). IEEE 